\title{
Overview of the 80th Scientific Sessions of the American Diabetes Association
}

\author{
Dr Caroline Day logs in to the meeting \\ relocated from Chicago to cyberspace \\ 12-16 June 2020
}

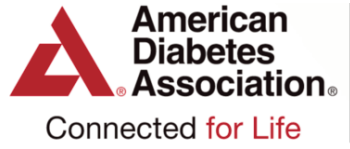

$80^{\text {TH }}$ SCIENTIFIC SESSIONS

A V I R TUAL EXPERIENCE

June 12-16, 2020

\section{Introduction}

In 2020 the wandering Wuhan virus went west, but when the World Health Organisation (WHO) declared COVID-19 a pandemic on 11 March 2020, only 245 new cases had been reported in the USA that day and there were fewer than 1,300 known cases of the virus in the country. Within a week the USA had cancelled travel from more than 26 European countries, making flying to Chicago more an aspiration than a potential. However, the number of new daily infections had risen to over 32,000 on 3 April when the ADA felt compelled to transition the 80th Scientific Session to online-only. Attendance at the 1st virtual Scientific Sessions was slightly dented with 12,537 delegates ( $>15,000$ in 2019), but the number of countries with representation increased to 134 (from 115 in 2019).

Previous Scientific Session abstracts, posters and webcasts can be accessed via https://professional.diabetes.org/contentpage/previous-scientific-sessions-abstractsposters-and-webcasts and, if only searching the 2020 meeting, go to https://plan.coreapps.com/tristar_ada20 or download the ADA Events app from the App Store/Google Play. Unfortunately, there is currently a charge attached to viewing the 2020 webcasts.

\section{Highlights}

As always, the named lectures are worth perusing (Table 1). It is easy to search the Abstracts and Sessions, using key words, to find detailed information on topics of interest. ADA 2020 Virtual Highlights (a sponsored site) can be accessed at www.adahighlights.com or download the app to get a detailed overview of the meeting.

Perhaps the highlight session at this year's ADA was the reporting of the cardiovascular outcomes trial (CVOT) VERTIS-CV with the sodium glucose co-transporter 2 inhibitor (SGLT2i) ertugliflozin. In this study over a median of 3 years 5,499 patients with established CV disease were randomised (1:1:1) to treatment with ertugliflozin (5 mg or 15 $\mathrm{mg} /$ day) or placebo, all in addition to usual care. Treatment with ertugliflozin was non-inferior (but not superior) to usual care with regard to the primary endpoint of a composite

Table 1 Awards 2020

$\begin{array}{ll}\text { National Scientific \& Health Care Achievement Awards and Lectures } & \text { Recipient } \\ \begin{array}{l}\text { Banting Medal for Scientific Achievement Award } \\ \text { Lecture: A journey in diabetes (14 June, 10.15am) }\end{array} & \text { Ele Ferrannini, Italy } \\ \begin{array}{l}\text { Kelly West Award for Outstanding Achievement in Epidemiology } \\ \text { Lecture: The epidemiology of hemoglobin A1c (14 June, 2.15pm) }\end{array} & \text { Elizabeth Selvin, USA } \\ \begin{array}{l}\text { Outstanding Scientific Achievement Award } \\ \text { Lecture: Emerging endocrine and paracrine hormones in health and } \\ \text { metabolic disease (15 June, 10.15am) }\end{array} & \text { Jiandie Lin, USA } \\ \begin{array}{l}\text { Outstanding Educator in Diabetes Award } \\ \text { Lecture: Tedious, and dull - an unrecognized problem that we can solve } \\ \text { (13 June, 10.15am) }\end{array} & \text { William H. Polonsky, USA } \\ \text { Outstanding Achievement in Clinical Diabetes Research Award } & \text { Bernard Zinman, Canada } \\ \text { Outstanding Physician Clinician in Diabetes Award } & \text { M Sue Kirkman, USA } \\ \text { Albert Renold Award } & \text { Elizabeth R Seaquist, USA } \\ \text { Harold Rifkin Award for Distinguished International Service in the Cause } & \text { Anne-Marie Felton, UK }\end{array}$
of Diabetes

\section{Professional Interest Group Award Lectures}

Edwin Bierman Award (Complications)

Lecture: Role of epigenetics in diabetic vascular complications and metabolic memory (13 June, $1.45 \mathrm{pm}$ )

Norbert Freinkel Award (Pregnancy)

Lecture: Paradigm shifts in the management of diabetes in pregnancy (13 June, $1.45 \mathrm{pm}$ )

Roger Pecorara Award (Foot Care)

Lecture: Collaboration for the advancement of diabetic foot research and education (14 June, 4.30pm)

Richard R Rubin Award (Behavioural Medicine \& Psychology) Lecture: Call the coach - opportunities and challenges for parent coaching in pediatric type 1 diabetes (13 June, 4pm)

\section{Recipient}

Ram Natarajan, USA

David Simmons, Australia

Lee J Sanders, USA

Randi Streisand, USA of CV death, non-fatal Ml or non-fatal stroke. However, treatment with ertuglifozin reduced hospitalisation for heart failure by 30\% (statistically significant, but not statistically valid due to the trial design mandating hierarchical statistical analyses), consistent with the apparent SGLT2i class effect to prevent and treat heart failure. Other data generated by VERTIS-CV such as renal endpoints were generally consistent (but not significant) with observations from the earlier SGLT2i CVOTs.

Moving from something new to something older - the Diabetes Prevention Program
Outcome Study (DPPOS) showed that 22 years after enrolling on the DPP (adults at very high risk of developing type 2 diabetes - now on average 72 years old), participants who were originally treated with lifestyle intervention or metformin were, respectively, $25 \%$ and $18 \%$ less likely to have developed type 2 diabetes than those on placebo. In participants who did not develop diabetes, these interventions significantly reduced the rates of eye $(57 \%)$ and kidney (37\%) disease. There was a reduction in major CV disease (39\%) and, in a subgroup of people who started the 
study before 45 years of age, metformin showed favourable trends in reducing stroke and CV events. Compared with placebo, metformin lowered the risk of cancer (12\%) and lifestyle intervention reduced the development of frailty.

\section{Diary date}

ADA 2021 is currently scheduled to take place at the Walter E Washington Conven- tion Center in Washington DC on 25-29 June (submit your abstract by 11 January). Hopefully it won't be necessary to again transition to a virtual meeting; despite session surfing from the sofa having its appeal (no last minute packing, no airline queues, no jetlag, no travel costs), there's no atmosphere, no physical networking and no opportunity for an actual visit to the aerospace museum.
Correspondence: Dr Caroline Day, Visiting Fellow, Diabetes Group, Aston University, Birmingham B4 7ET, UK E-mail: cday@mededuk.com

http://dx.doi.org/10.15277/bjd.2020.273 Br J Diabetes 2020;20:169-170 